\title{
Design of Advanced Integrated Reactor Protection System for Commercial Fast Breeder Reactor
}

\author{
M. Sivaramakrishna ${ }^{1} \&$ Manish Kumar $^{2}$ \\ ${ }^{1}$ Indira Gandhi Centre for Atomic Research, Department of Atomic Enrgy, Kalpakkam, India \\ ${ }^{2}$ School of Nuclear Energy, Pandit Deendayal Petrolium University, Gandhinagar, India \\ Correspondence: M. Sivaramakrishna, Indira Gandhi Centre for Atomic Research, Department of Atomic Enrgy, \\ Kalpakkam, Tamilnadu, India. Tel: 91-44-2748-0500. E-mail: sivarama@igcar.gov.in
}

Received: March 21, 2012 Accepted: June 26, 2012 Online Published: October 26, 2012

doi:10.5539/emr.v1n2p82

URL: http://dx.doi.org/10.5539/emr.v1n2p82

\begin{abstract}
Shutdown systems are one of the most important one for the safety of the reactor core. In case of any abnormal event or any parameter going abnormal or otherwise, it trips the reactor. Hence this system should be highly reliable. The reliability of the Present shutdown system could not be improved beyond a certain limit, due to many interconnections between the sub systems in the safety chain. i.e. Different sensors, processing electronics, safety logic are located physically at different and far off locations connected with cables, passing through cable trays, penetrations and buildings. New design configuration has been proposed, where there is only single system (PCB) comprising of processing electronics and comparison with thresholds, with voting logic built into the control rods itself. This eliminates the need for one exclusive safety logic system. With this design, the reliability promised to be more than the existing system, without the need for more than one shutdown system. With this design, the reliability promised to be more than the existing system, without the need for more than one shutdown system. The thesis discusses the details of the design made and improvements in the reliability factor.
\end{abstract}

Keywords: PFBR, FBR, shutdown system, CFBR, safety system, reliability

\section{Introduction}

Department of Atomic Energy (DAE) has prepared action plan to set up 5 Fast Breeder Reactors each of 500 MWe capacities by 2020. Prototype Fast Breeder Reactor (PFBR) is the forerunner of the second stage of India's three stage nuclear power program. PFBR is $500 \mathrm{MWe}$, mixed oxide fuelled, sodium cooled pool type reactor.

Reactor safety logic system is designed to initiate safety action against Design Basis Events (DBE). Reactor shutdown system is intended to protect the reactor from neutronic and thermal Incidents. In case of any abnormal event or any parameter going abnormal or otherwise, it trips the reactor. Hence this system should be highly reliable.

In the present system, sensors and the control rods are located adjacent to each other. But the connection is through various intermediate stages. These stages are located physically at different places.

A dedicated system is required for performing the $2 / 3$ voting logic, i.e. safety logic. Hence, again separate testing logic is required to test the healthiness of the safety logics. Diverse routes are required for the cable routing for the A, B, C channels. Penetrations are required for the cables to pass through in route. The reliability of the entire shutdown system could not be improved beyond $10^{-6} \mathrm{R} / \mathrm{y}$ even with two diverse safety logics connected to diverse shutdown system working on diverse parameters.

Therefore the reliability of the present shutdown system could not be improved beyond a certain limit, due to many interconnections between the sub systems in the safety chain. i.e. Different sensors, processing electronics, safety logic are located physically at different and far off locations connected with cables, passing through cable trays, penetrations and buildings. Hence new design has been proposed with different configuration.

\section{Shutdown System of PFBR}

In the present design as shown in Figure1, Prototype Fast Breeder Reactor (PFBR) is provided with two independent fast acting and diverse shutdown systems (SDS), namely SDS1 and SDS2 to detect any abnormalities in reactor core and to initiate safety action. Each system is capable of shutting down the reactor 
independently. Each SDS consists of Sensors, Signal Processing Systems, Safety Logic Systems, Drive Mechanisms and Absorber Rods. Absorber rods of SDS-1 are called Control and Safety Rods (CSRs) and theabsorber rods of SDS-2 are called as Diverse Safety Rods (DSRs).There are 9-CSRs and 3-DSRs.CSRs are used for startup, control of reactor power, controlled shutdown and SCRAM, where as DSRs are used only for SCRAM. The respective drive mechanisms are called as Control \& Safety Rod Drive Mechanism (CSRDM) \& Diverse Safety Rod Drive Mechanism (DSRDM).

There are two diverse safety logic systems. Safety Logic with Fine Impulse Test (SLFIT) is provided for shutdown system with CSRDM as shown in Figure2 and Pulse Coded Safety Logic (PCSL) is provided for DSRDM. SLFIT design is based on One-Time Programmable Logic Devices (FPGAs)as in Figure3. Solid State Logic may fail in fail-safe mode or fail-danger mode (i.e. stuck at ' 0 ' or stuck at ' 1 '). In order to detect these faults, an on line test facility i.e. FIT is provided. Since majority of faults in solid state logic result in static conditions, PCSL is a dynamic logic, which has inherent fail-safe design. In PCSL, each redundant channel of trip parameters is combined with unique coded pulse train. This pulse train labels the individual inputs in such a way that the status of each input can always be identified. All stages of the logic are continuously exercised by these coded pulse trains which check every logical combination, thus providing continuous on-line testing. Optical cross-link shall be provided between the SLFIT and PCSL at the output stage.

Each system is connected to processing electronics which measure the core Temperature, Neutronics, Delay neutron Detection (DND) and Power to Flow Ratio. The voting logic is local 2/3 on each parameter. Reactor safety logic receives the trip signals from neutronics flux monitoring, core temperature monitoring, failed fuel detection, core flow monitoring system and processes them in a logical fashion to give command for initiating reactor shutdown. The analogue output signals from these core monitoring systems are converted into binary signal in a comparator, which form the inputs to the safety logic. This system de energizes the EM-Coils and dropping the absorber rods of both the systems under gravity whenever a trip parameter crosses its threshold limits or if there is a demand for reactor shut down.

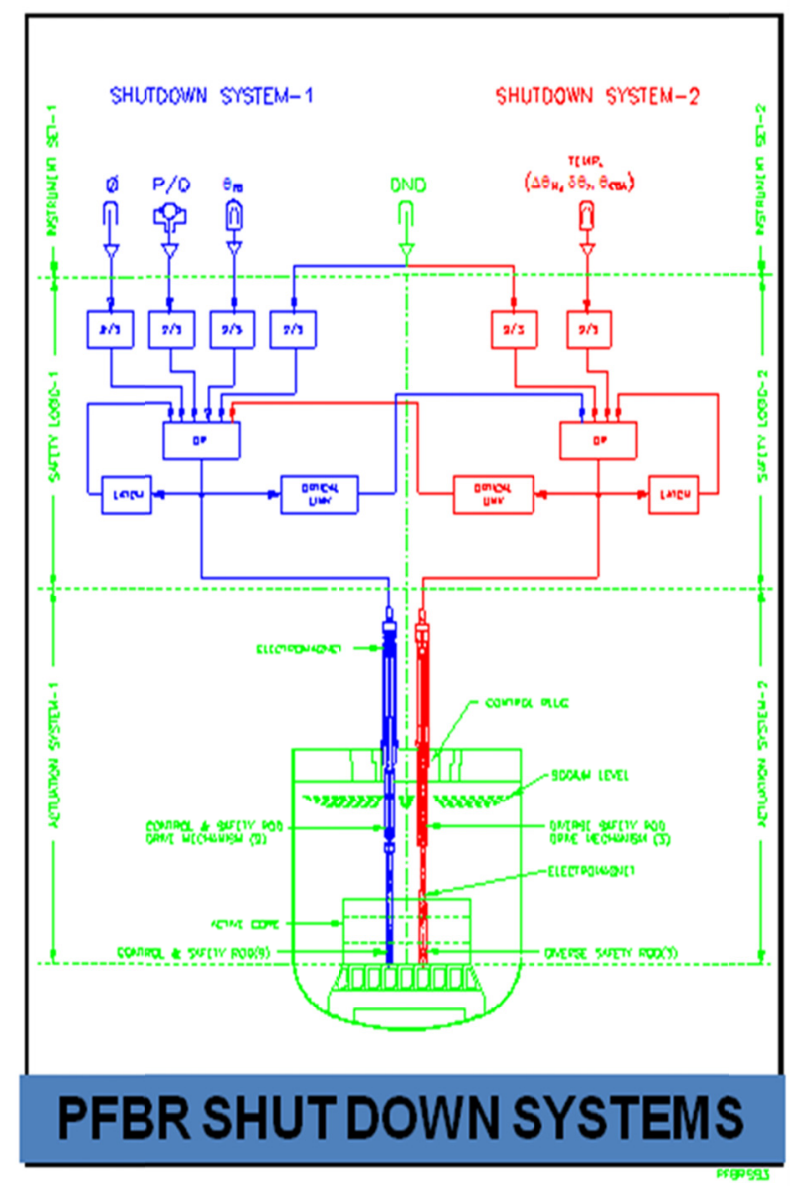

Figure 1. PFBR shutdown systems 


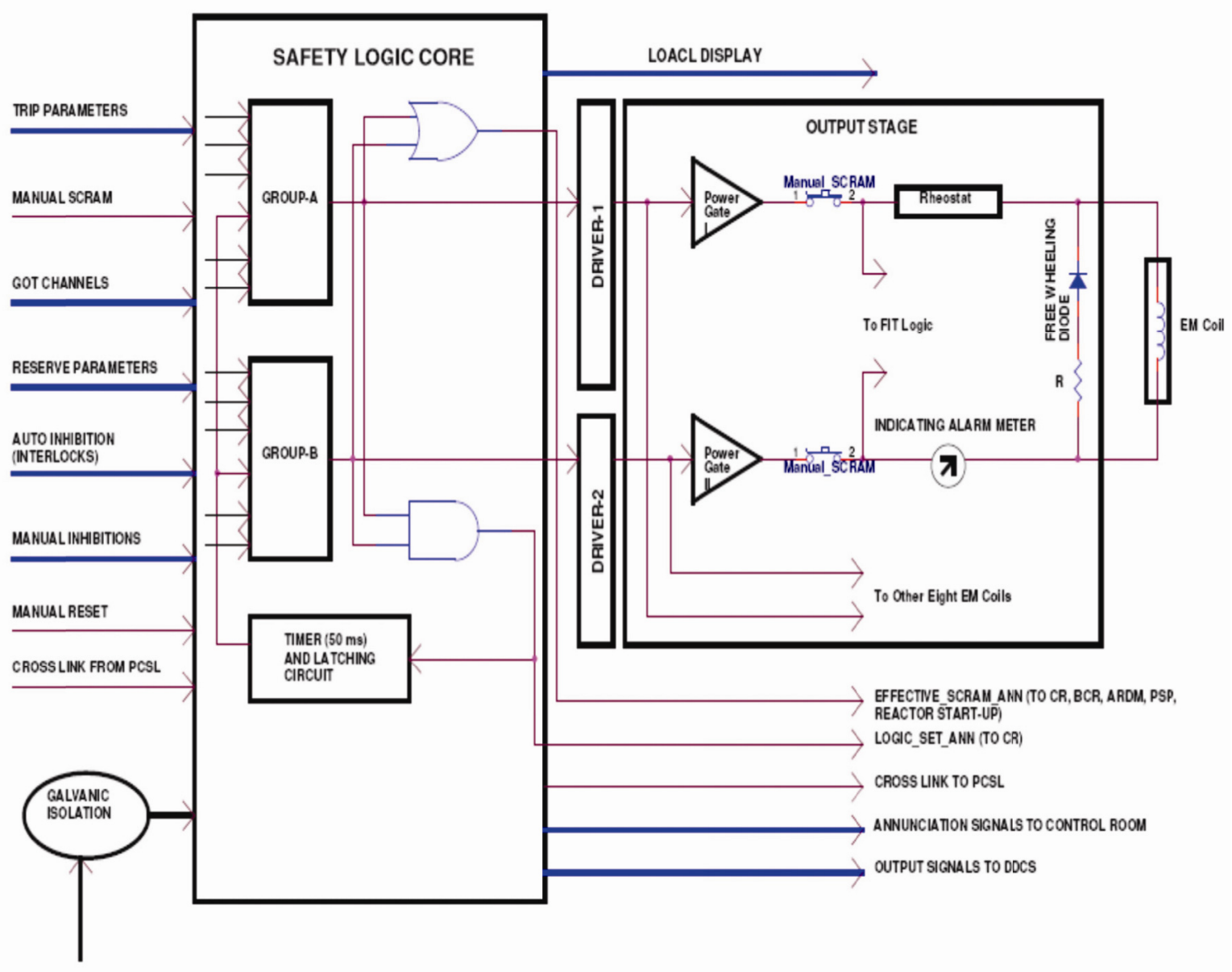

SIGNALS FROM FIT LOGIC

Figure 2. Block diagram of safety logic with FIT (SLFIT)

\section{PCSL for Multiple Parameters}

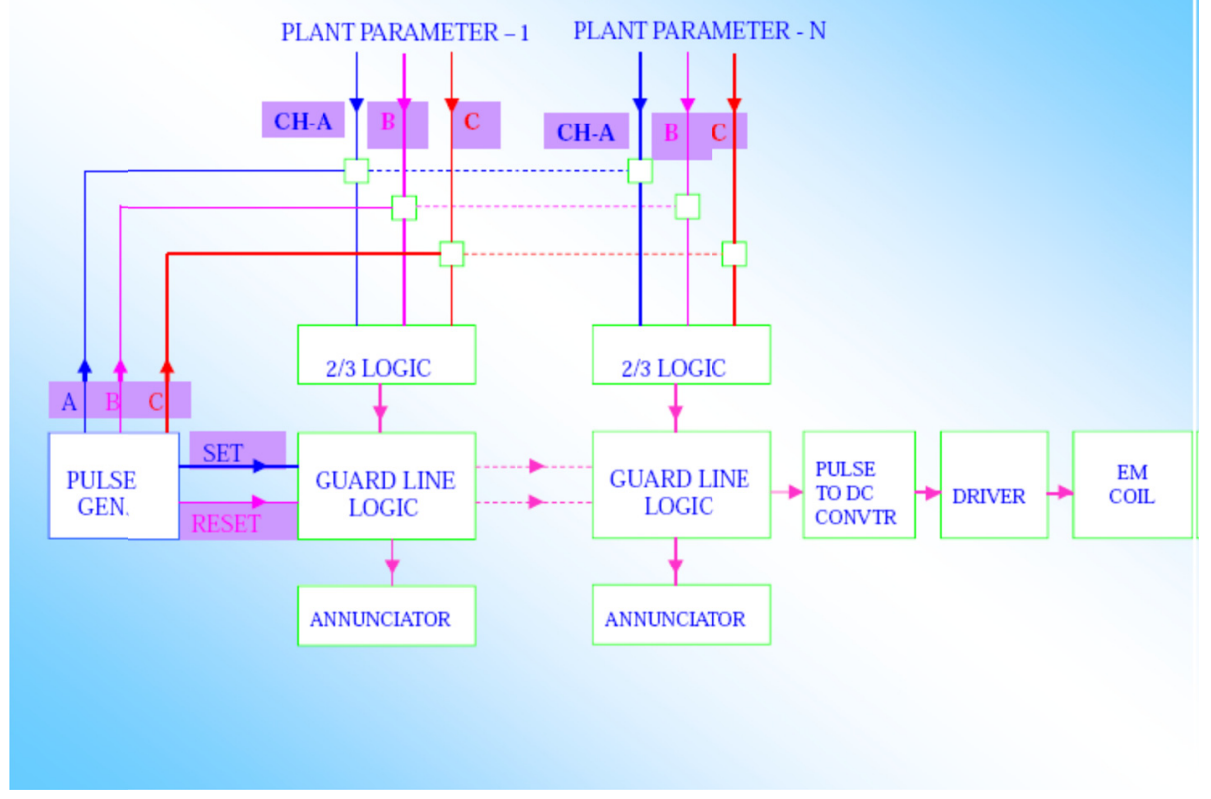

Figure 3. Block diagram of safety logic with PCSL 


\section{Shutdown System of CFBR}

In PFBR shutdown system, for every diverse function a different circuits and logics are provided. For example to provide redundancy $2 / 3$ logic has been incorporated and therefore a different PCB is dedicated specially for $2 / 3$ logic. Similarly, a special circuit is designed based on PCSL principle particularly for online testing of healthiness of the system. Such a design principle requires more number of components and interconnections within the circuits. Therefore, the complexity of the system gets increased which finally affect the reliability of the system. However the sensors and control rods are located adjacent to each other. But connection is done through various intermediate stages and these stages are located physically at different places and for their interconnection lengthy cables are required. The SCRAM signals may be affected by noise due to the lengthy cable. Diverse routes are required for the cable routing for the A, B, C channels. Penetrations are required for the cables to pass through in route. Hence the reliability of the entire shutdown system could not be improved beyond $10^{-6} \mathrm{R} / \mathrm{y}$ even with two diverse safety logics connected to diverse shutdown system working on diverse parameters.

Therefore, the basic concept of this new design is to reduce the number of components and interconnect them in parallel phase, to the extent possible and decrease complexity thus increasing the reliability of the system as flow diagram of new design is shown in Figure4.

In new design configuration only single system (PCB) comprising of processing electronics and comparison with thresholds along with voting logic built into the control rods itself. This eliminates the need for one exclusive safety logic system. With this design, the reliability promised is better than the existing system, without the need for more than one shutdown system. The block diagram of new design is shown in Figure5 and the complete circuit in Figure6.

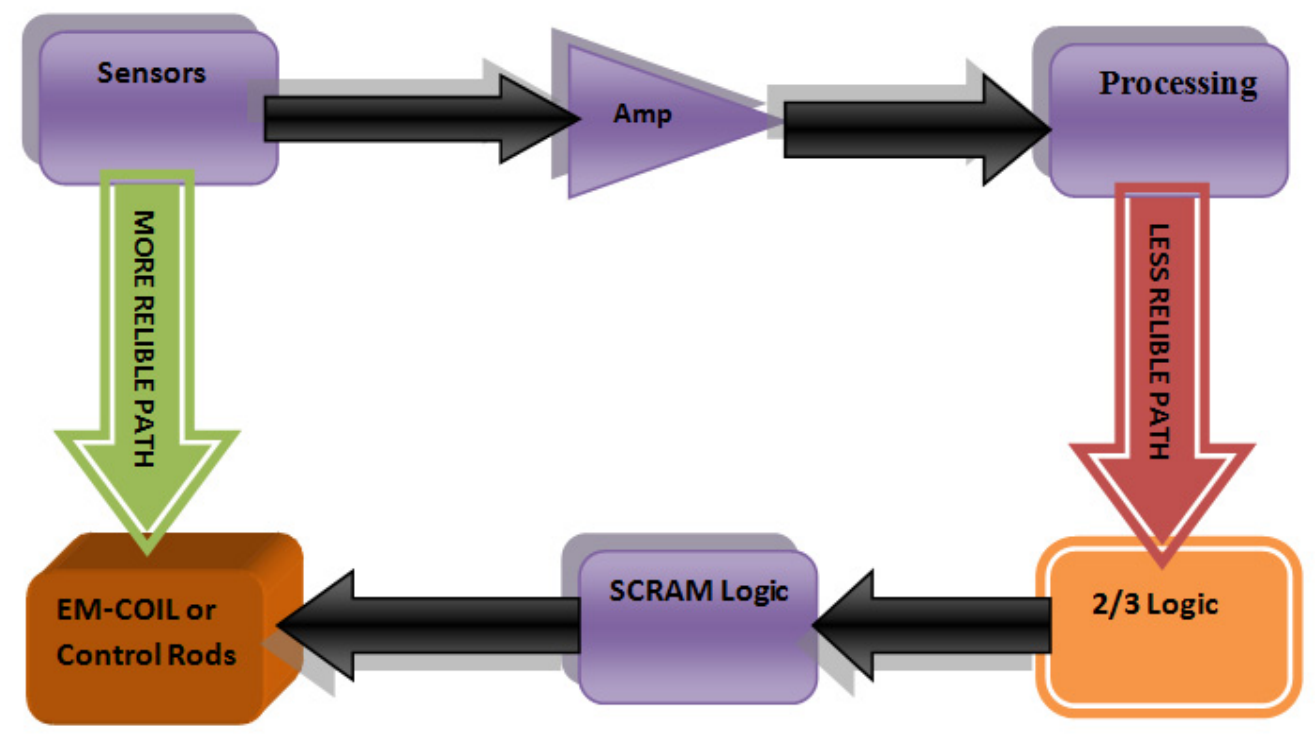

Figure 4. Flow diagram of shutdown system 


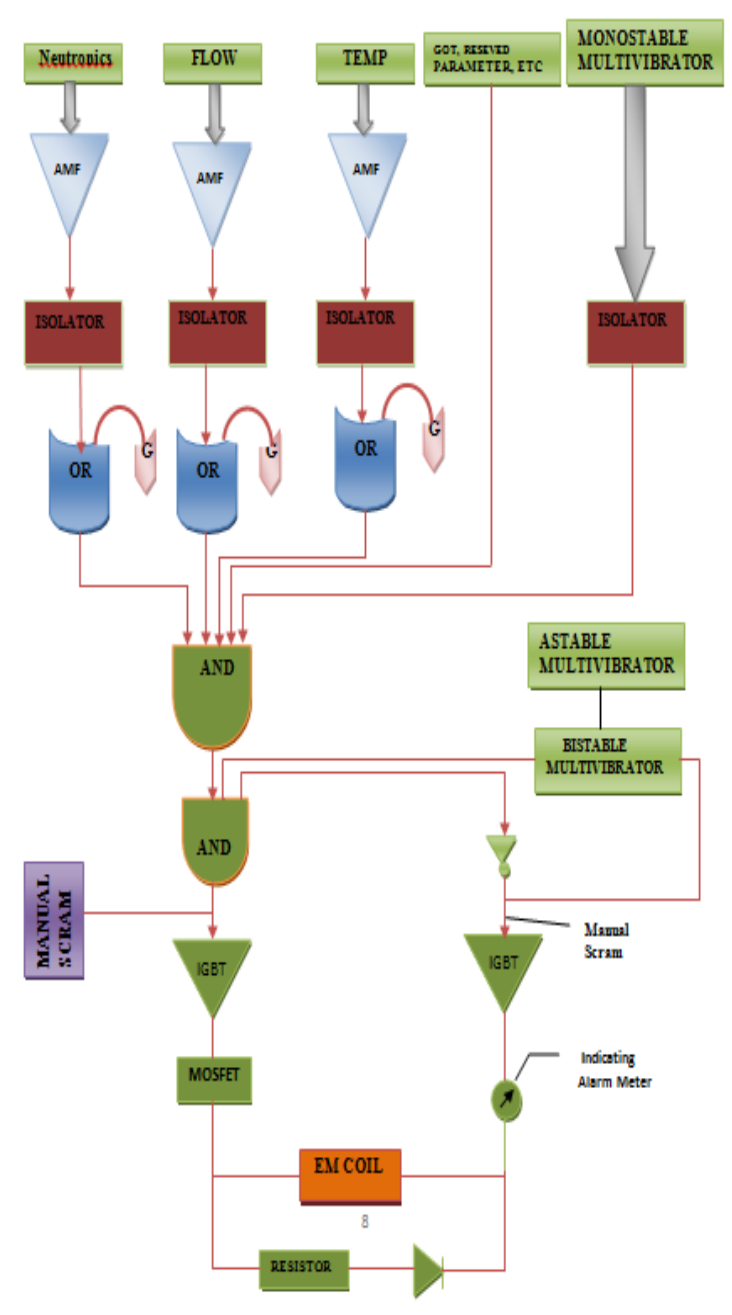

Figure 5. Block diagram of CFBR shutdown system

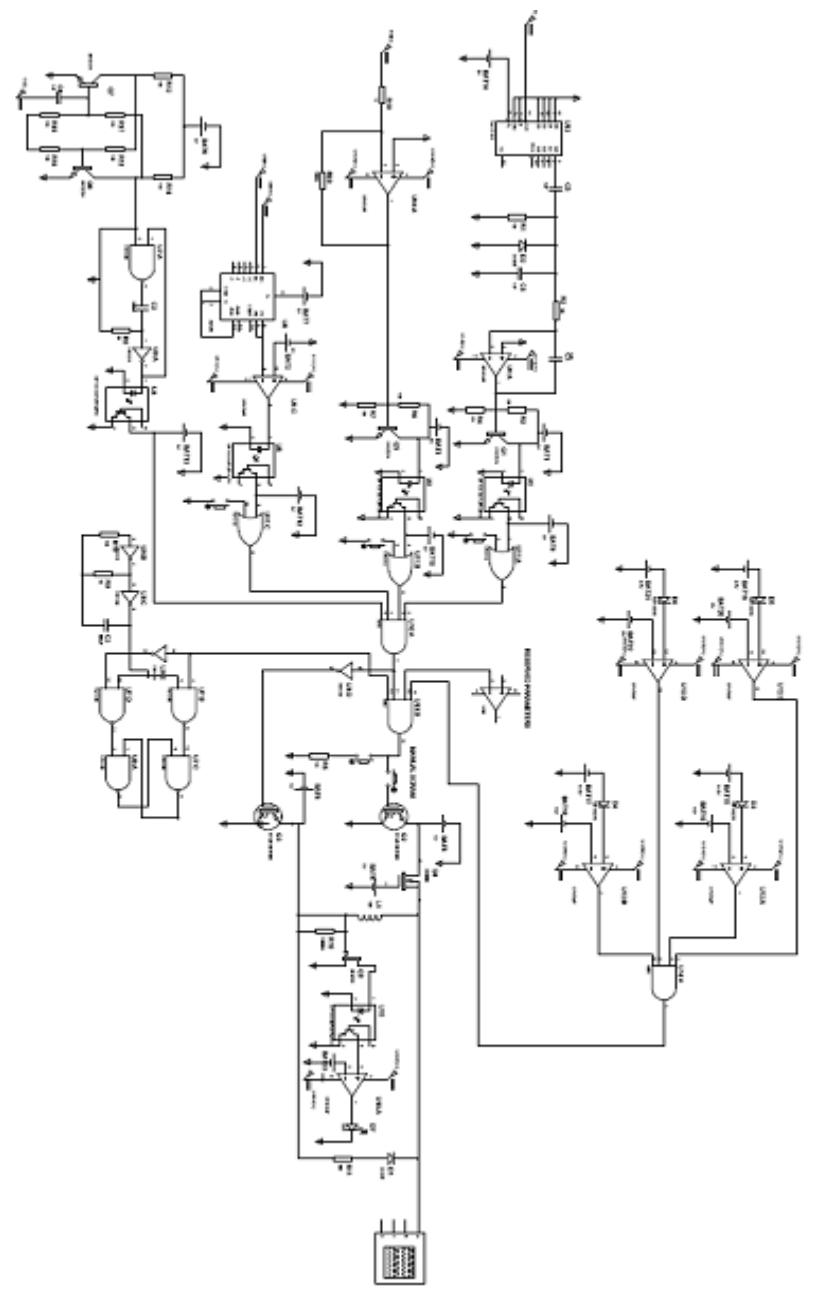

Figure 6. Flow diagram of shutdown system

\subsection{Function of Different Components}

The three most important parameters to be monitored in a reactor are Neutronics, temperature and flow. These are always maintained within the specified range to ensure the safety of the reactor. If any of these crosses the threshold limits SCRAM is actuated.

\subsubsection{Neutronics}

Neutronic signals are used to measure the power of the reactor. The analog signal obtained from the neutronic instrumentation is converted to digital signal with the help of integrator. The digital output is fed to voltage divider circuit working as a switch which gives output to SCRAM signal if the value obtained through the logic signal is ' 0 '. The threshold for neutronics is $1 \mathrm{uA}$. The complete circuit diagram of the nutronics circuit is shown in Figure7.

\section{Calculations:}

i. Integrator Part:

$$
\frac{\mathrm{d} V_{o u t}}{d t}=-\frac{\mathrm{d} V_{i n}}{R C}
$$

Therefore,

$$
V_{o u t}=\int_{0}^{t} \frac{V_{i n}}{d t}+V_{\text {initial }}
$$


ii. Voltage Divider Circuit

$$
\begin{gathered}
\mathrm{I}_{\mathrm{B}}=\frac{\mathrm{V}_{\mathrm{TH}}-\mathrm{V}_{\mathrm{BE}}}{\mathrm{R}_{\mathrm{B}}+(1+\beta) \mathrm{R}_{\mathrm{E}}} \\
\mathrm{V}_{\mathrm{CE}}=\mathrm{V}_{\mathrm{CC}}-\mathrm{I}_{\mathrm{C}}\left(\mathrm{R}_{\mathrm{C}}+\mathrm{R}_{\mathrm{E}}\right) \\
\mathrm{V}_{\mathrm{TH}}=\frac{\mathrm{R}_{2} \mathrm{~V}_{\mathrm{CC}}}{\mathrm{R}_{2}+\mathrm{R}_{1}}
\end{gathered}
$$

Where, $R_{B}=R_{1} / / R_{2}$

The resistance is connected is such a way that the transistor is work as a switch. On the basis of voltage divider output logic SCRAM is decided as follows

Normal state: Logic ' 1 ', andSCRAM state: Logic ' 0 ' for trip channels

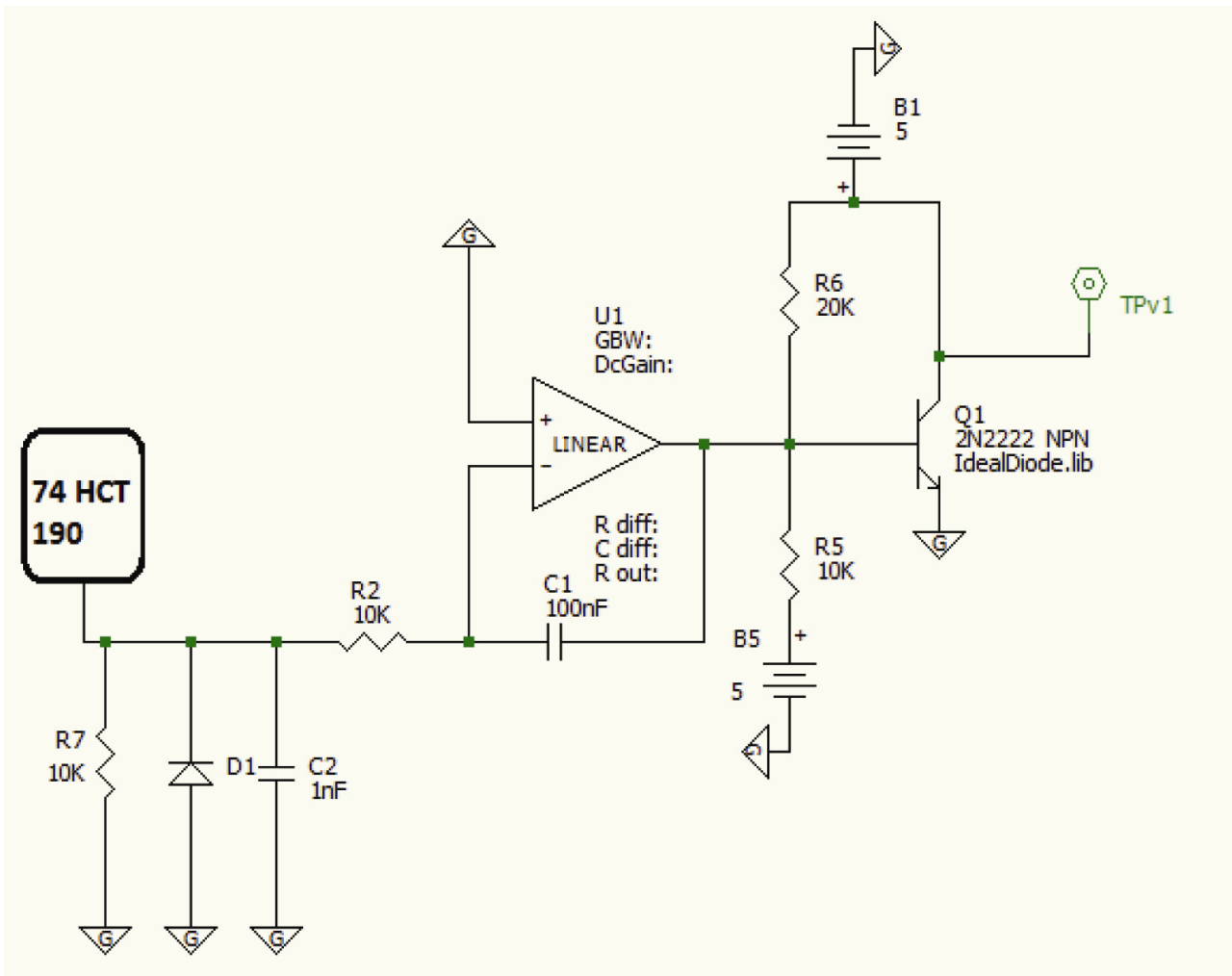

Figure 7. Circuit diagram for nuetronics

\subsubsection{Flow}

One of the most important parameter of the reactor is primary coolant flow. Power from the fuel is extracted by the flow of Sodium through the core. The circuit diagram for flow arrangement is shown in the Figure8. The digital value obtained from the PMMC flowmeter is amplified by a gain of 1000 and then compared. If the value obtained is less than $5 \mathrm{~V}$ SCRAM signal is actuated.

Gain

$$
\frac{V_{o}}{V_{i n}}=\frac{R_{F}}{R_{1}}
$$




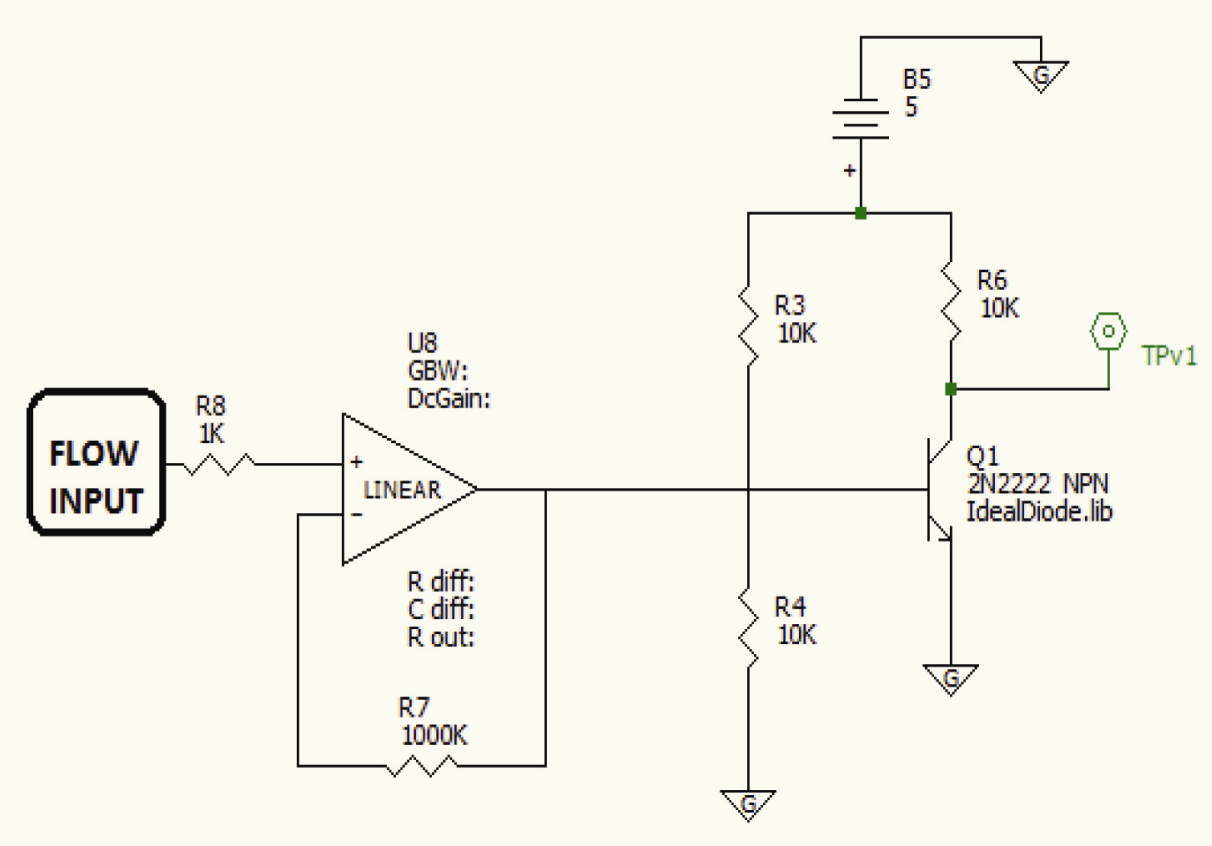

Figure 8. Circuit diagram for flow

\subsubsection{Temperature}

Temperature of outlet sodium from the core is measured so as to ensure that fuel safety limits are never breached. The temperature signal from K- type thermocouple installed is converted in a voltage signal through IC AD 595 as shown in Figure 9. It is then compared with the threshold 2 to $10 \mathrm{~V}$ of the comparator as in Figure10.

The IC AD 595 has following features:
a. Low power : $<1 \mathrm{nW}$ typical
b. Wide power supply range : $+5 \mathrm{~V}$
c. Built in IC point compensation.
d. Low impedance voltage Output $10 \mathrm{mV} / \mathrm{c}$
e. Thermocouple failure alarm.

Since TPv $1=10^{\wedge} 6(5-\mathrm{i} / \mathrm{p})$ Where $10^{\wedge} 6$ is the gain of op- amp.

If $i / p>5 \mathrm{~V}$, Then $(5-i / p)$ will positive,

Therefore TPv $1=+$ Saturation and generate Logic ' 1 '.

Similarly, if $\mathrm{i} / \mathrm{p}<5 \mathrm{~V}$, Then ( $5-\mathrm{i} / \mathrm{p}$ ) will Negative,

Therefore TPv $1=-$ Saturation and generate Logic ' 0 '. 


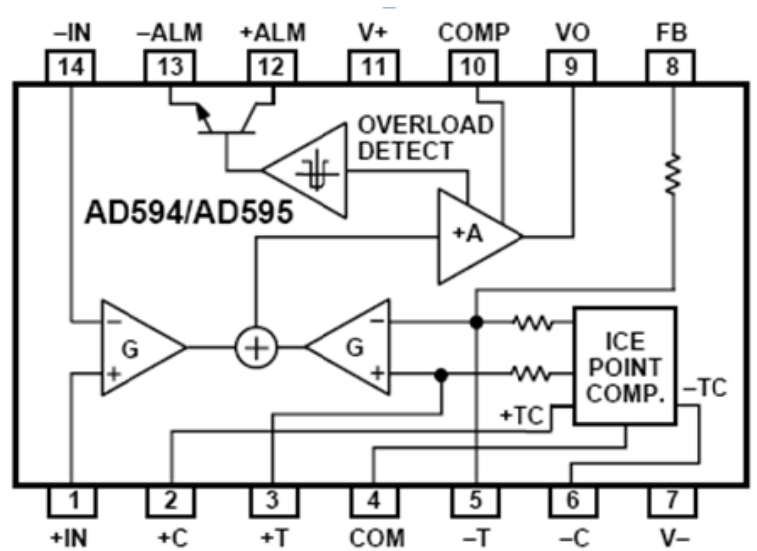

Figure 9. IC AD 595

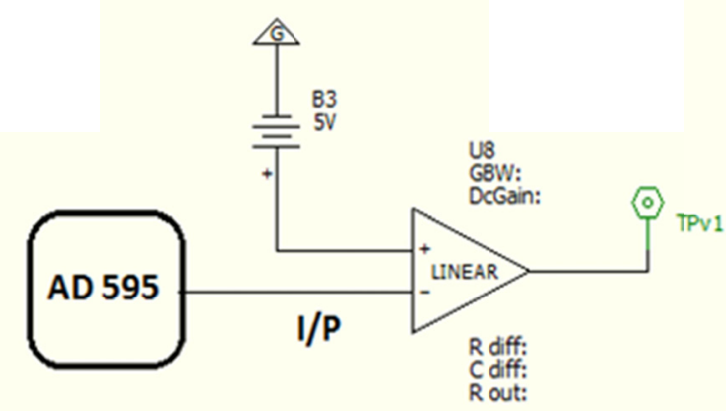

Figure 10. Circuit diagram for comparator

\subsubsection{Monostable Multivibrator}

Monostablemulivibrator is connected to provide testability as Figure11. It works as a Pulse Generator whose generates pulses of time period of $1 \mathrm{sec}$. It continuously generates the pulse after 1 second who continuously checks the healthiness of the system.

Pulse pattern: A train of fine pulses of duty cycle $1 \mathrm{~ms}$ with time period 1 to 10 second shall be generated in the pulse generator as in Figure 10. We are taking here time period of 1 second.

The corresponding value of Capacitor and Resistance for $1 \mathrm{sec}$ is

Since, $\mathrm{T}=0.69 \mathrm{RC}$, Therefore $\mathrm{C}=1 / 0.69 \mathrm{R}$,

If we take $\mathrm{R}=3 \mathrm{~K}$ Then $\mathrm{C}=500 \mathrm{uF}$ 


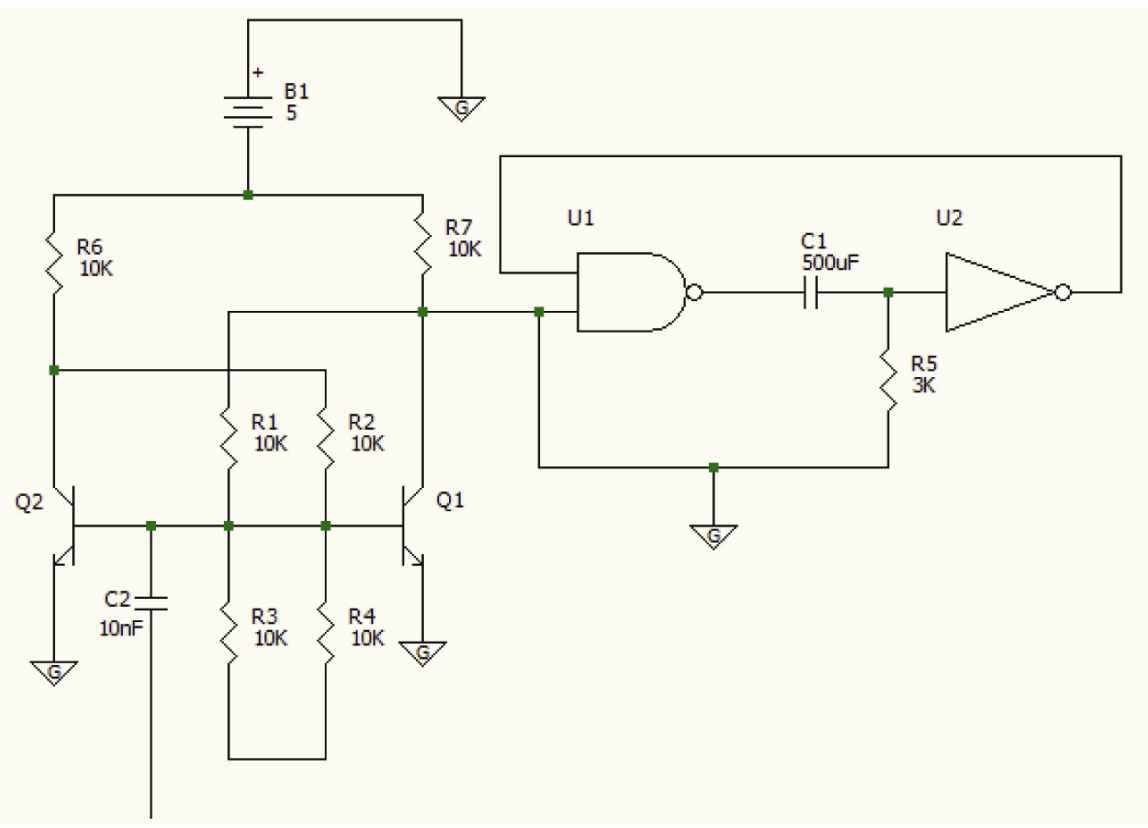

Figure 11. Circuit diagram for monostable multivibrator

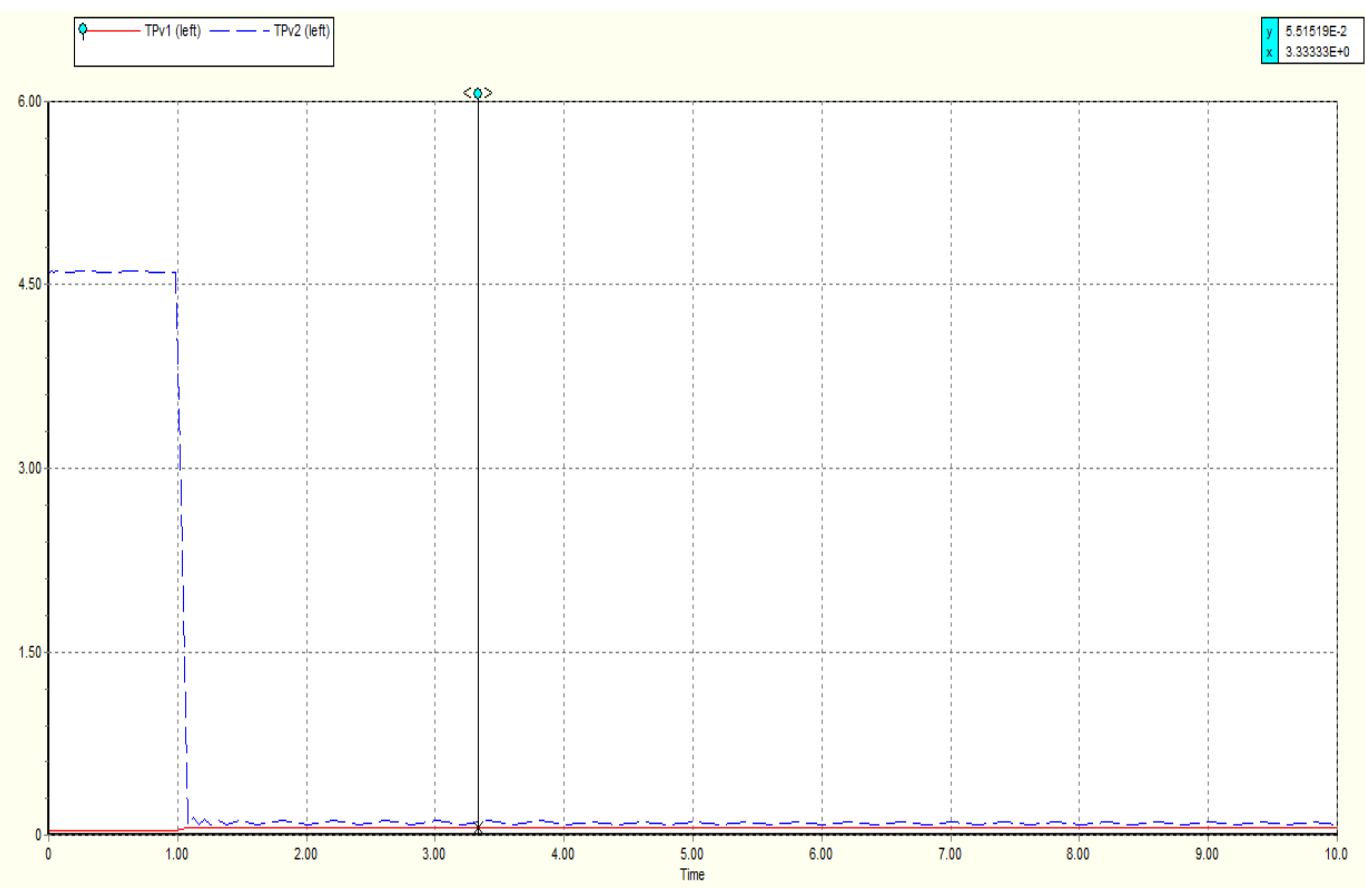

Figure 12. Monostable multivibrator output

\subsubsection{Bistable Multi Vibrator (Latching of Trip Order)}

Latching circuit shall be basically a memory circuit. Latching circuit shall be provided to avoid partial control rod drop and spurious trips. It shall have a memory-reset provision. Latching circuit shall be provided to memorise trip signal if the trip signal duration is more than $50 \mathrm{~ms}$ as in Figure 13. EM coils have different response times from $80 \mathrm{~ms}$ to $120 \mathrm{~ms}$. Hence, a trip order with a short duration may cause dropping of some control rods, which have fast EM coil response time, whereas some other control rods with longer EM coil response time may not drop. The purpose of the latching circuit is to latch the trip order of duration greater than 
$50 \mathrm{~ms}$, thereby preventing partial rod drop. Since, Timer and Latching circuit is not connected in the series with the Grouping stage and EM-coil drive circuit. Hence, it's not introducing any delay in the trip order.

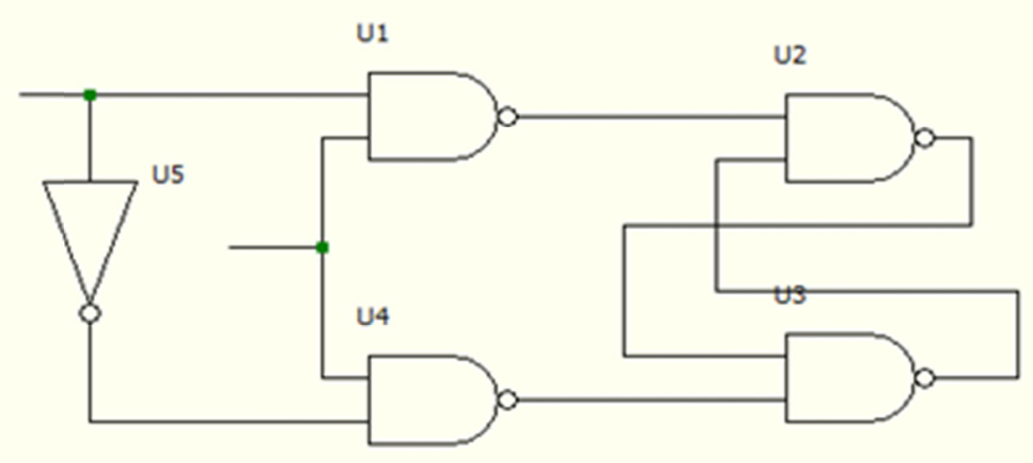

Figure 13. Circuit diagram for bistable multivibrator

\subsubsection{Astable Multivibrator}

Here astablemultivibrator is provided for Reset. Which is mounted in safety logic panel in CR (control room) shall be used to reset the memory only when all the trip parameters are in normal condition. Latching circuit shall not delay trip order. The circuit diagram and the waveform is shown in the Figure 14 and Figure 15 respectively. The duty cycle for reset signal may be take anything between 1 to $10 \mathrm{sec}$. Suppose we are taking reset time $3 \mathrm{sec}$. then, the corresponding value of Capacitor if we are taking a resistor of $3 \mathrm{~K} \mathrm{ohm} \mathrm{Since} \mathrm{T}=$ $2.2 \mathrm{RC}=3 \sec \mathrm{C}=500 \mathrm{uF}[$ for $\mathrm{R}=3 \mathrm{~K}$ ]

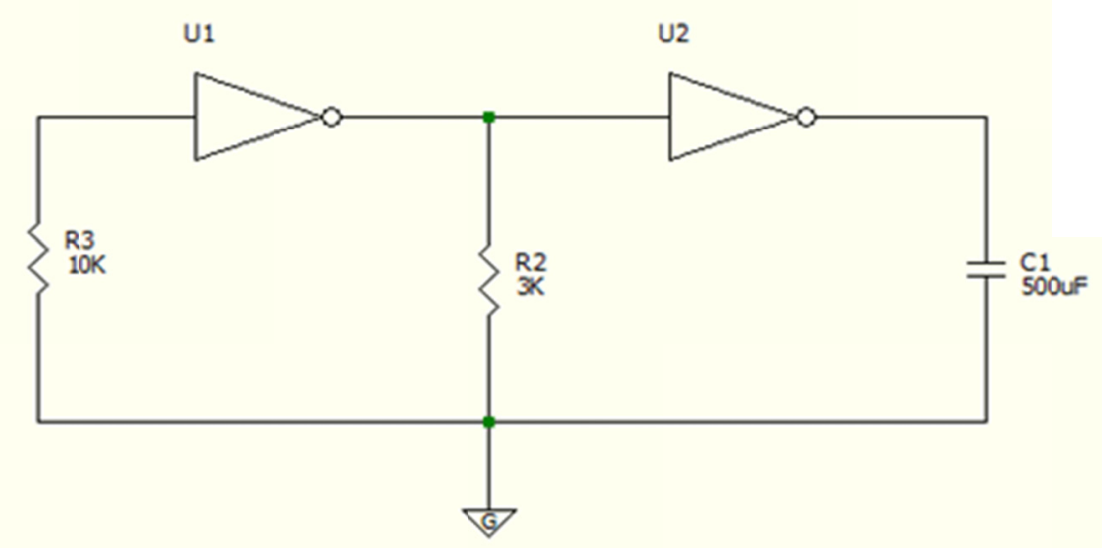

Figure 14. Circuit diagram for astable multivibrator 


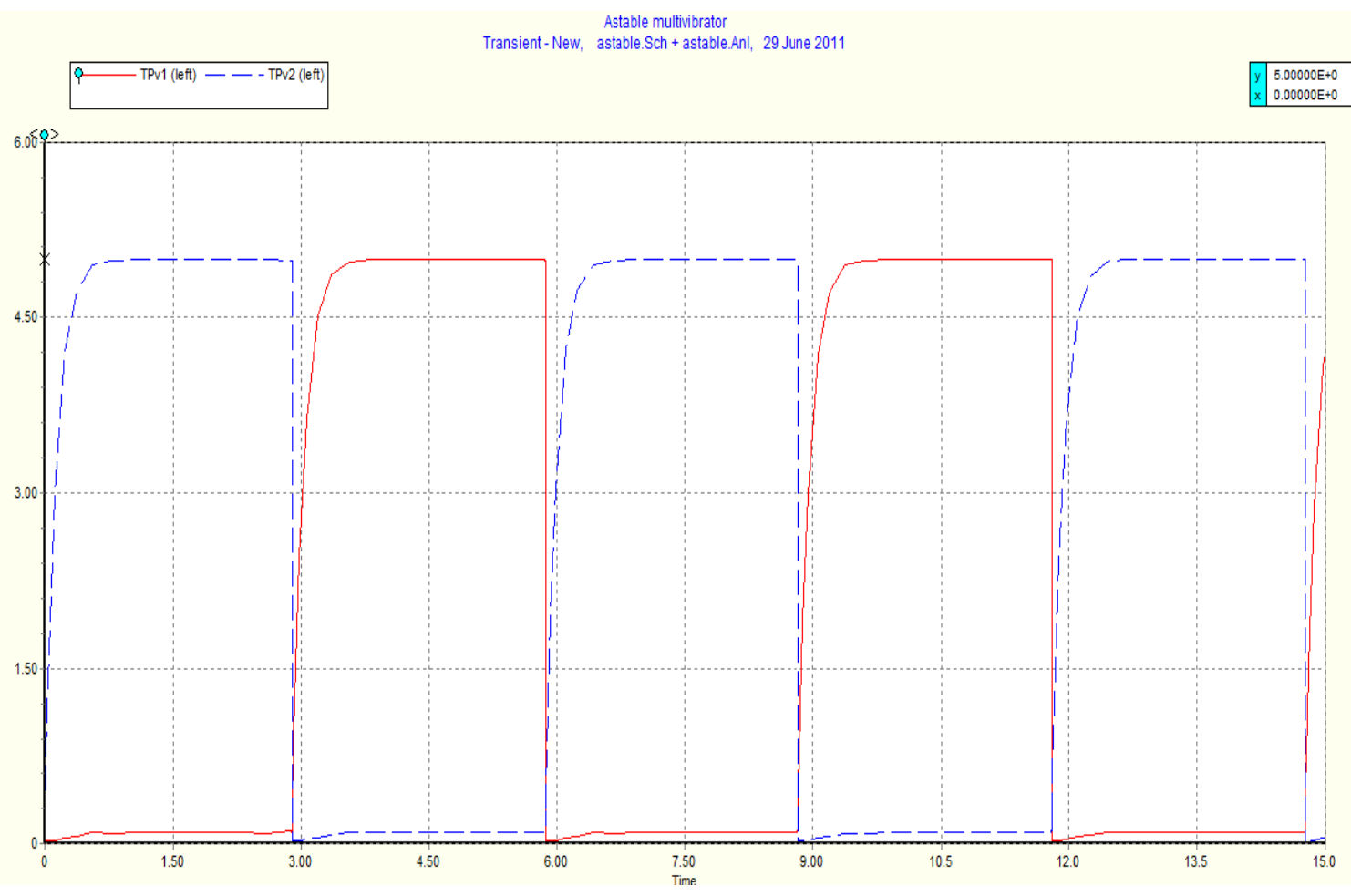

Figure 15. Output of astable multivibrator

\subsubsection{Opto-Isolatior}

Each trip parameter shall be galvanically isolated from trip channels and fault-detectionlogic with opto-isolators.It safe the circuit through high voltage or fluctuation of voltage. Here $4 \mathrm{~N} 35$ optoisolator is used as Figure16.

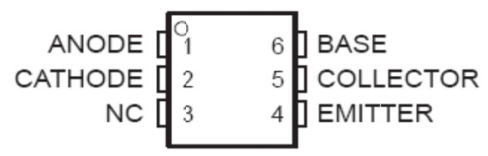

Figure 16. IC 4N35

\subsubsection{Indicating Alarm Meters (IAM)}

A separate Indicating Alarm Meter indicates the current in each EM coil. These meters shall have facility to generate an alarm, whenever the EM coil current falls below a set limit i.e less than holding current. Each meter shall have two set points to generate two alarms. One set point at high current is required to indicate that the EM coil is energized. The corresponding relay contact of the current meter shall be wired to Reactor start-up system. The second set point at low current is required to indicate that the EM coil is de energized. The corresponding relay contact of the current meter shall be wired to Fuel Handling start-up system. Therefore this shows the low current in EM coil. The no of such IAM shall be equal to the no of EM coils. The set limits can be set by the operator manually

\subsubsection{2/3 LOGIC}

This design has not any separate PCB specially dedicated for $2 / 3$ logic as previous. Here $2 / 3$ voting logic built into the control rods itself. We design a coil whose operating current carrying capacity will be $1 \mathrm{~A}$ to $1.5 \mathrm{~A}$ as in Figure 15 and The current flowing by each PCB in the coil is 0.5 .Therefore if any two PCB will be damage then less than 1 A current will flow from the coil and finally SCRAM will be actuated. 


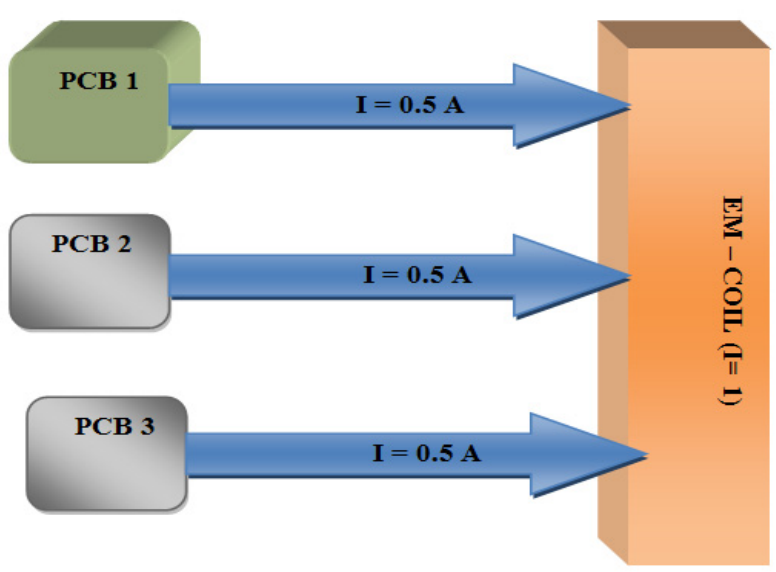

Figure 17. Block diagram of 2/3 Logic

\subsubsection{Free Wheeling Diode}

A free wheeling diode shall be connected across each EM coil to suppress the back-EMFgenerated due to switching of IGBTs. Direct connection of diode across the coil causes increase in drop time. A resistor of $300 \Omega$ shall be connected in series with the diode as a compromise between effective surge suppression and fast drop time.

\subsubsection{Manual Scram}

Manual SCRAM is an operator command from Control Room (CR) and Back-up Control Room (BCR) to initiate fast shut down of the reactor under specific conditions. The Manual SCRAM over rides all logic conditions and de-energizes all the Electro-magnet (EM) coils when the push button is actuated from either Control Room (CR) or Back-up Control Room (BCR). Here the push button input is converted to Relay contacts, which are connected in series with the EM coils.

\subsubsection{Mosfet}

Since rheostat is bulky in size therefore it is replaced by MOSFET which is work as a active resistance. It provides to control the EM coil currents. Indicating Alarm Meters (IAM) is provided to show the current as well as to alarm if current goes below to set limits. Relays are provided to cut the coil current directly on Manual SCRAM.

\subsection{Power Supply}

We take DC to DC converter of $48 \mathrm{~V}(+10 \%,-15 \%)$ class-I power supply and converted it in $+15 \mathrm{~V},-15 \mathrm{~V}$, $+5 \mathrm{~V},-5 \mathrm{~V}$.

\subsection{Data for Power Gates Design}

Number of EM coils : 12

i) Operating current range of EM coil :1 A to $1.5 \mathrm{~A}$

ii) EM coil resistance: $7.5 \mathrm{~W}$ at $298 \mathrm{~K}\left(25^{\circ} \mathrm{C}\right)$.

iii) Ambient temperature range in which EM coils are operated : $298 \mathrm{~K}$ to $353 \mathrm{~K}$

iv) EM coil lead resistance : negligible

\subsection{Response Time}

Response time of Safety Logic shall not exceed $1 \mathrm{~ms}$ in response to a SCRAM order (excluding the response time of EM-Coil) i.e. from the instant SCRAM order is issued to safety logic, the de-energization of EM coil shall start within $1 \mathrm{~ms}$.

\subsection{Adaptability}

Reserve parameters shall be provided for adding SCRAM parameters in future, if required.

\section{Design Principle}

The safety logic system design is meeting all the basic design principle as follows: 
1) Redundancy: Three parallel PCB are connected to a coil and each PCB is capable of shutting down the reactor independently. We can also connect extra coil or control rod to provide redundancy.

2) Fail-safe: Pull-down resistor is use in eachinput stage. Therefore if any component becomes fail due to any cause the current is passes in ground by pull down resistor and the reactor shutdown automatically.

3) Isolation: Each input and output is connect with Galvanic isolator to provide isolation the circuit.

4) Independence: Three parallel PCB are connected to a coil and Each PCB provided different Power Supply. There is no any relationship between the three PCB which is connected to a coil. Therefore each PCB is capable of shutting down the reactorindependently.

5) Testability: A Monostablemulivibrator is connected to provide testability. It works as a Pulse Generator whose generates pulses of time period of $1 \mathrm{sec}$. It continuously generates the pulse after 1 second who continuously checks the healthiness of the system.

6) Diversity: Three different PCB is connected to a single coil as in Figure16. Here Logic is design using basic gates, digital and analog circuits. We can design the other two PCB using DSP and microprocessor for providing diversity.

All the components used are standard and has fast response time. A $300 \mathrm{ohm}$ resistance is connected to the coil for provide fast response to the coil.

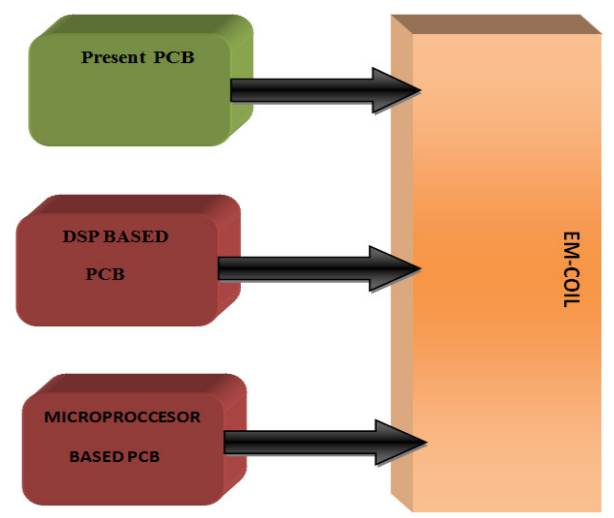

Figure18. Block diagram for diversity principle

\section{Reliability Calculations ofthe CFBR Shutdown System}

Reliability is the probability of a system or device performing its purpose adequately for the period of time intended under the operating conditions encountered. Reliability prediction is done here using the standard handbook of reliability prediction of Electronic equipment MIL-HDBK-217-F notice-2.

The realibility of individual component of the design is

- $\quad$ The nutronics instrument $=0.097200$

- $\quad$ The flow instrument $=0.097522759$

- $\quad$ The temperature instrument $=0.097203$

- Bistablemultivibrator $=0.015075$

- Astablemultivibrator $=1.688$

- $\quad$ Mono multivibrator $=0.09720000639$

- $\quad$ NOT Gate $=0.015075$

- $\quad$ AND Gate $=0.015075$

- $\quad$ AND Gate $(\mathrm{MOS})=0.0252$

- $\quad$ OR Gates $=0.015075$

- $\quad$ Power Gate $=0.008316$

- Mosfet $=0.008316$ 


\section{Results}

Reliability of the circuit in different cases is

(i) The failure rate of the actual circuit without $2 / 3$ logic is $\lambda_{\mathrm{P}}=0.7352053945 * 10^{-9}$ Failure $/ 10^{6} \mathrm{hrs}$

(ii) The failure rate of the actual circuit with $2 / 3$ logic is $\lambda_{\mathrm{P}}=3 R^{2}-2 R^{3}$, Where $\mathrm{R}$ is the reliability of the circuit without $2 / 3$ logic Therefore, $\lambda_{\mathrm{P}}=0.1621580914 * 10^{-17}$ Failure $/ 10^{6} \mathrm{hrs}$ and $\lambda_{\mathrm{P}}=0.1621580914 * 10^{-16}$ Failure/ year

(iii) If all the components is connected in series then reliability of the circuit without $2 / 3$ logic is $\lambda_{\mathrm{P}}=0.51279162$ Failure $/ 10^{6} \mathrm{hrs}$

(iv) If all the components is connected in series then reliability of the circuit with $2 / 3$ logic is $\lambda_{\mathrm{P}}=0.5191700$ Failure/ $10^{6} \mathrm{hrs}$

(v) If only Nutronics, Temperature and Flow are connected in parallel and all other components are connected in series then reliability of the circuit with $2 / 3$ logic is

$\lambda_{\mathrm{P}}=0.2217822690207$ Failure $/ 10^{6} \mathrm{hrs}$

(vi) Actual circuit with 10 times more components without 2/3 logic is

$\lambda_{\mathrm{P}}=0.696336$ Failure/ $10^{6} \mathrm{hrs}$

(vii) Actual circuit with 10 times more components with $2 / 3$ logic is

$\lambda_{\mathrm{P}}=0.145465147 * 10^{-8}$ Failure $/ 10^{6} \mathrm{hrs}$

$\lambda_{\mathrm{P}}=0.145465147 * 10^{-8}$ Failure/year

\section{Conclusion}

With this design, the reliability promised to be more than the existing system even taking worse case without the need for more than one shutdown system. New design configuration has only single system (PCB) comprising of processing electronics and comparison with thresholds, with voting logic built into the control rods itself. It also fulfills all the basic principle of design of safety point of view. This design is more simple and compact because the entire bulky element like rheostat and $2 / 3$ logic is totally removed from this design. The reliability of the previous design was $10^{\wedge}(-6)$ where as the reliability of this design is $10^{\wedge}(-8)$ Even taking worse case i.e connecting 10 times more components to the design.

\section{References}

IAEA. (1996). TECDOC No. 866 - Feb 1996, Fast breeder database, page 129, Retrived from IAEA website.

IAEA, (1988). TECDOC No. 478-1988, Component Reliability for use in probabilistic safety assessment, Retrived from IAEA website.

US DOE, MIL-HDBK-217F notice 2, Reliability prediction of electronic equipment, Retrived from MIL HANDBOOK website. 